\title{
Nanostructural, Chemical, and Mechanical Features of nc-Si:H Films Prepared by PECVD
}

\author{
Jong-Ick Son, Hee-Jong Nam, and Nam-Hee Cho \\ Department of Materials Science and Engineering, Inha University, Incheon, Republic of Korea \\ Correspondence should be addressed to Nam-Hee Cho, nhcho@inha.ac.kr
}

Received 29 August 2011; Revised 26 November 2011; Accepted 5 January 2012

Academic Editor: Junsin Yi

Copyright ( 2012 Jong-Ick Son et al. This is an open access article distributed under the Creative Commons Attribution License, which permits unrestricted use, distribution, and reproduction in any medium, provided the original work is properly cited.

This study examined the effects of film thickness on the nanostructural, chemical, and mechanical features of nc-Si:H films deposited by plasma-enhanced chemical vapor deposition. $\mathrm{SiH}_{4}$ and $\mathrm{H}_{2}$ were used as the source gases, and the deposition time was varied from 10 to $360 \mathrm{~min}$. The mean nanocrystallites size in the Si films increased from $\sim 6$ to $\sim 8 \mathrm{~nm}$ with increasing film thickness from 85 to $4150 \mathrm{~nm}$. Moreover, the nanocrystallite concentration and elastic modulus increased from $\sim 7.5$ to $\sim 45 \%$ and from 135 to $147 \mathrm{Gpa}$, respectively. In the $4150 \mathrm{~nm}$ thick film, the relative volume fraction of Si nanocrystallites and relative fraction of $\mathrm{Si}-\mathrm{H}$ bonds in the films were approximately $\sim 45 \%$ and $\sim 74.5 \%$, respectively.

\section{Introduction}

Recently, the development of renewable energy systems has attracted considerable attention due to the high oil price and the safety risk of nuclear power systems. In particular, the transformation of solar energy into electrical power is one of the most important scientific and industrial issues mainly because solar energy is clean, infinite, and nontoxic [1]. Among the many types of thin films used in solar devices, hydrogenated nanocrystalline silicon (nc-Si:H) thin films have promising features, such as controllable energy band gap, light absorption coefficient, and electrical conductivity. All these features depend critically on the characteristics of nanometer-sized Si crystallites embedded in an amorphous matrix $[2,3]$. For such applications, nc-Si:H thin films have been fabricated mainly by plasma-enhanced chemical vapor deposition (PECVD) $[4,5]$.

Solar cells based on amorphous silicon thin films consist of p-type, n-type, and intrinsic amorphous silicon layers. The intrinsic layer plays an important role in enhancing the solar cell efficiency [6]. For the intrinsic a-Si:H layers in solar cells, the nanostructural features of the intrinsic layers need to be well controlled in terms of the Si nanocrystallite size and size distribution. The relationship between the film thickness and the efficiency of solar cells has been reported previously $[7,8]$. Nevertheless, few studies have examined the effect of the film thickness on the nanostructural, chemical, and mechanical features of the films. In addition, with varying film thickness, the mechanical stress within the film needs to be examined to better understand the nanostructural characteristics of a-Si:H films.

In this study, nc-Si:H films were deposited on Si wafers by PECVD and the formation of Si nanocrystallites along with their nanostructural, chemical, and mechanical features were examined in terms of the film thickness. Local variations in the nanostructural features and mechanical and chemical properties of thick films were also examined using a nanoprobed electron beam.

\section{Experimental Details}

The nc-Si:H thin films were deposited on a $\mathrm{Si}(001)$ wafer and a slide glass at room temperature by PECVD. $\mathrm{SiH}_{4}$ and $\mathrm{H}_{2}$ were introduced into a chamber at 4 and $96 \mathrm{sccm}$, respectively, and were activated with a RF power source. The RF power and frequency were $150 \mathrm{~W}$ and $13.56 \mathrm{MHz}$, respectively. The substrate temperature was fixed to room temperature. The surface of the substrate $\mathrm{Si}$ wafer was cleaned in a HF solution to remove the native oxide layer. Table 1 provides details of the deposition conditions for the films. 
TABLE 1: Various deposition conditions of the nc-Si:H thin films.

\begin{tabular}{ccc}
\hline System & Deposition parameter & Experimental conditions \\
\hline & $\mathrm{SiH}_{4}$ flow rate $(\mathrm{sccm})$ & 4 \\
& $\mathrm{H}_{2}$ flow rate $(\mathrm{sccm})$ & 96 \\
& Substrate & Si wafer, glass \\
PECVD & RF power (watt) & 150 \\
& Deposition time (min) & $10,30,60,180,360$ \\
& Working pressure & $4 \times 10^{-2}$ (Torr) \\
& Background pressure & $1 \times 10^{-6}$ (Torr) \\
\hline
\end{tabular}

The size and relative volume fraction of Si nanocrystallites in the films were examined by Raman spectroscopy (Hobin Yvon, T6400). The film thickness was measured by field emission scanning electron microscopy (FESEM, Hitachi, S-4300). High-resolution X-ray diffraction (HRXRD, XPET-PRO MDR) was performed to estimate the mean nanocrystallite size in the films. The chemical bonds of the films were analyzed by Fourier Transform Infrared (FTIR, IFS66v/s, Bruker) spectroscopy. High-resolution transmission electron microscopy (HRTEM, JEOL 2100F) and electron energy loss spectroscopy (EELS) were used to obtain local structural information. Electron microdiffraction was used to identify the presence of crystallites at particular regions of the films; the beam probe was $\sim 1 \mathrm{~nm}$ in size. Cross-section TEM specimens $(\sim 8 \mu \mathrm{m} \times \sim 6 \mu \mathrm{m} \times \sim 40 \mathrm{~nm})$ were prepared from a $4150 \mathrm{~nm}$ thick film using a focused ion beam (FIB) technique. The Young's modulus of the films was analyzed using a nanoindenter (MTS, Nanoindenter XP).

\section{Results}

3.1. Nanostructural Features. Figure 1 shows cross-section SEM images of the nc-Si:H thin films. The film thickness increased almost linearly from 85 to $4150 \mathrm{~nm}$ with increasing deposition time from 10 to $360 \mathrm{~min}$. (Figure $1(\mathrm{~d})$ ). The interface between the film and substrate is clearly noticeable, and column-shaped morphology features were observed in the film region.

Figure 2 shows XRD patterns of the nc-Si:H films. The diffraction peak at $28.4^{\circ} 2 \theta$ was assigned to the (111) crystallographic plane of Si. The Si (111) peak intensity increased with increasing deposition time. In particular, the intensity of the peak in spectrum (5) was 8 times as large as that in spectrum (1). The crystallite size was estimated using Sherrer's equation [9].

$$
d_{\mathrm{XRD}}=\frac{0.9 \lambda}{B \cos \theta}
$$

where $\lambda$ is the X-ray wavelength, $B$ is the FWHM, and $\theta$ is the diffraction angle of the peak. The crystallite size varied from $\sim 6$ to $\sim 8 \mathrm{~nm}$. This variation was clearly observed within the resolution of the analysis method.

The Raman spectra of the nc-Si:H films deposited for 10, 180, and $360 \mathrm{~min}$, were obtained (Figure 3). All phonon modes of the transverse acoustic (TA), longitudinal acoustic (LA), longitudinal optical (LO), and transverse optical (TO) modes are active in Raman spectroscopy [10]. The best Gaussian fits of the Raman spectra are illustrated in each spectrum. The broad peak at $480 \mathrm{~cm}^{-1}$ indicates the presence of amorphous silicon (a-Si). The shoulder peak at $500 \sim 510 \mathrm{~cm}^{-1}$ was assigned to the presence of $\mathrm{Si}$ nanocrystallites (nc-Si) [11]. The symmetric main peak of bulk $\mathrm{Si}$ is centered at $521 \mathrm{~cm}^{-1}$.

Deconvoluted Gaussian fits provide information on the volume fraction of the nanocrystallites as well as the mean crystallite size. Equation (2) was used to obtain the mean crystallite size $[12,13]$.

$$
D_{\text {Raman }}=2 \pi \sqrt{\frac{\beta}{\Delta \omega}},
$$

where $\Delta \omega$ is the peak shift for the Si nanocrystallite compared to that of bulk $\mathrm{Si}$ and $\beta=2.0 \mathrm{~cm}^{-1} \mathrm{~nm}^{2}$. The Raman spectra of the nc-Si:H films deposited for $10 \mathrm{~min}$ clearly show the characteristic features of amorphous Si. With increasing deposition time from 30 to $360 \mathrm{~min}$, there was a significant variation in crystallite size from 6.9 to $8.5 \mathrm{~nm}$. The results obtained by XRD and Raman spectroscopy were well matched to each other; the difference was less than $1 \mathrm{~nm}$ for each size.

The volume fraction $X_{c}$ of the Si nanocrystallites in the films was obtained based on two fits: one $\left(I_{a}\right)$ near $480 \mathrm{~cm}^{-1}$ and the other $\left(I_{c}\right)$ for $\mathrm{nc}$-Si. The relative volume fraction of Si crystallites in the film was estimated by the formula, $X_{c}=I_{c} /\left(I_{c}+\eta I_{a}\right)$, where $\eta$ is a scattering factor that is regarded as $\sim 1.0$ for nanocrystallites [14]. The volume fraction of nanocrystallites increased steadily with increasing film thickness. The largest fraction was observed in the $4150 \mathrm{~nm}$ thick films; the fraction was approximately $\sim 45 \%$.

3.2. Chemical Bonding Features. Figure 4 shows the FT-IR spectra of the nc-Si:H films prepared for (a) 30, (b) 60 and (c) $360 \mathrm{~min}$. The spectra were deconvoluted and the best fits are illustrated. The spectra show prominent peaks at 2000, 2100 , and $2140 \mathrm{~cm}^{-1}$, which were assigned to a stretching vibration of $\mathrm{Si}-\mathrm{H}$ (monohydride), $\mathrm{Si}-\mathrm{H}_{2}$ (di-hydride) and $\mathrm{Si}-\mathrm{H}_{3}$ (tri-hydride), bonds, respectively [15]. $\mathrm{Si}-\mathrm{H}_{2}$ bonds were dominant in the films prepared for $30 \mathrm{~min}\left(X_{c}=7.5 \%\right)$, whereas the $\mathrm{Si}-\mathrm{H}$ and $\mathrm{Si}-\mathrm{H}_{3}$ fractions were quite small. In contrast, the films with $X_{c}=45 \%$ contained a high proportion of $\mathrm{Si}-\mathrm{H}$, whereas the $\mathrm{Si}-\mathrm{H}_{2}$ and $\mathrm{Si}-\mathrm{H}_{3}$ fractions were quite small. The $\mathrm{Si}-\mathrm{H}$ bond can be attributed to the passivation of Si crystallites embedded in an amorphous Si matrix [16]. The Si crystallites on the surface can be surrounded by hydrogen producing monohydrides. On the other hand, dihydrides and trihydrides bonds are easily returned to the plasma or remain in the amorphous phase of the films. The presence of monohydride type bonds in the films indicates the enhancement of Si crystallization. The relative fraction of monohydrides with respect to the total hydrides in the film increased to $\sim 74.5 \%$ with increasing film thickness to $4150 \mathrm{~nm}$. 


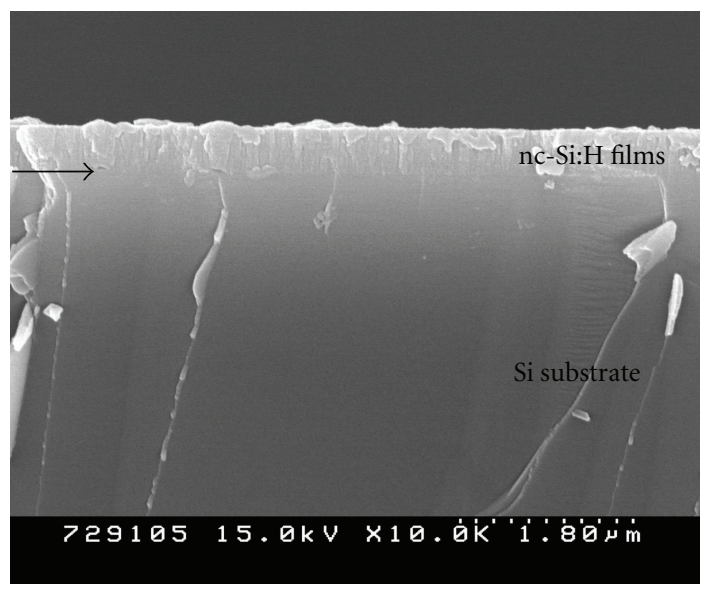

(a)

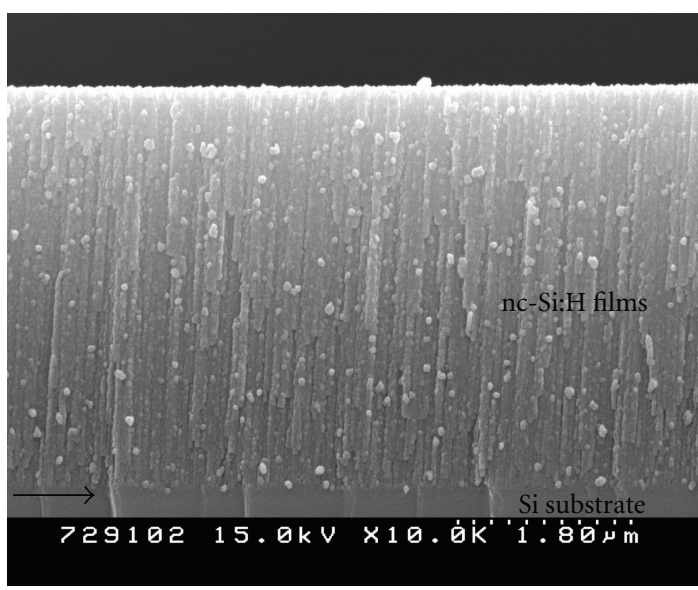

(c)

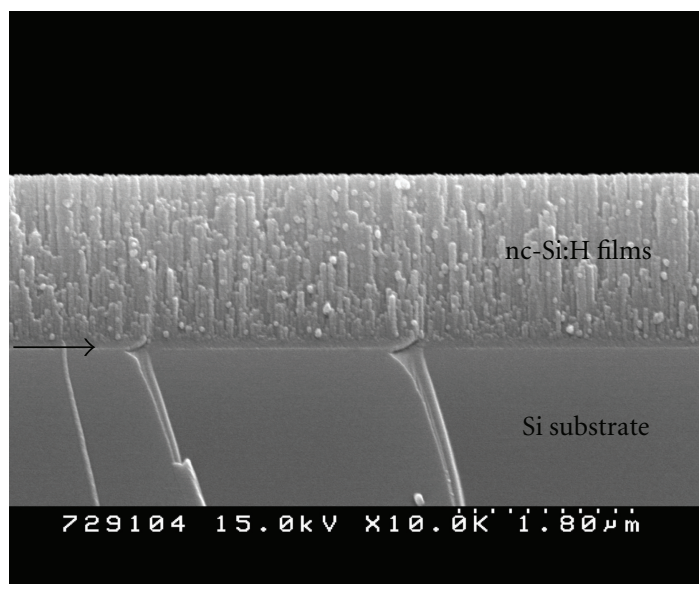

(b)

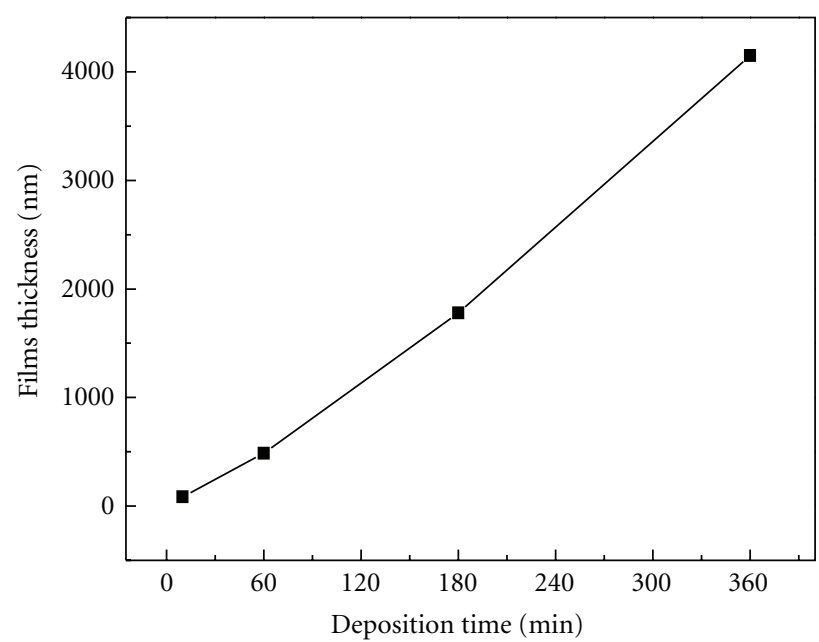

(d)

FIGURE 1: Cross-section SEM images of the films. The films were prepared for 60 (a), 180 (b), and 360 min. (c), respectively. (d) Film thickness versus deposition time. The arrows indicate the interface between the films and Si substrate.

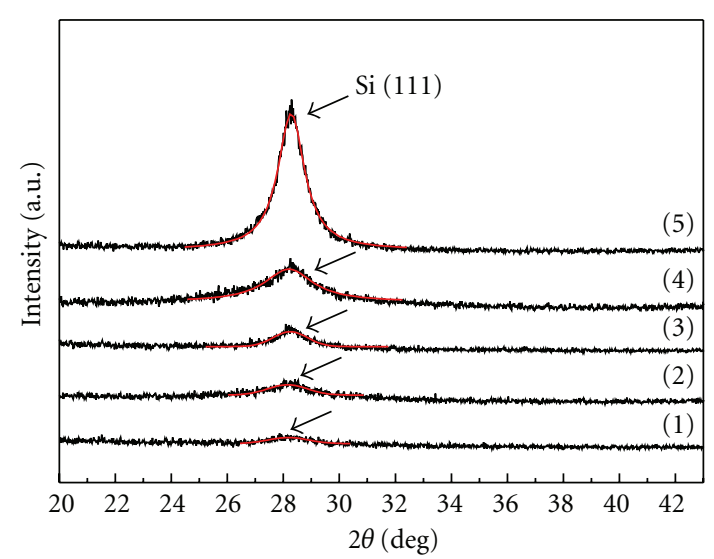

(a)

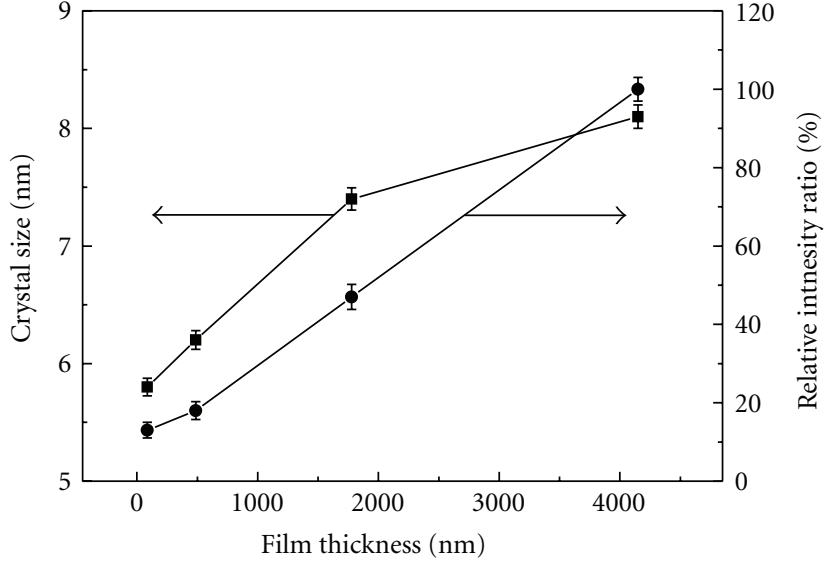

(b)

Figure 2: (a) XRD patterns of the Si thin films. The films were prepared at a substrate temperature of R.T. for 10 (1), 30 (2), 60 (3), 180 (4), and $360 \mathrm{~min}$ (5), respectively. The arrow indicates the presence of (111) Si peaks in each spectrum. (b) Crystal size and relative peak intensity ratio $\left(\right.$ relative peak intensity ratio $=\left(\right.$ Intensity $_{\text {peak } 1,2,3,4,5} /$ Intensity $\left.\left._{\text {peak } 5}\right) \times 100 \%\right)$ versus film thickness. 


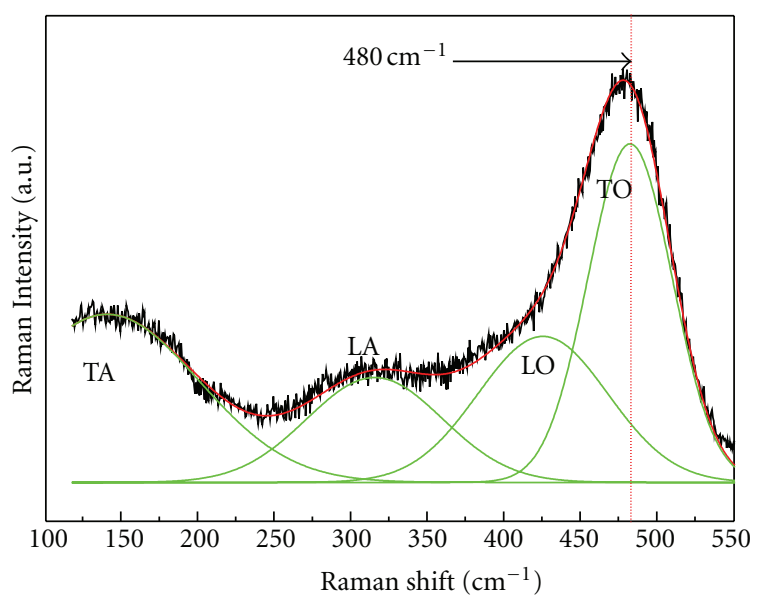

(a)

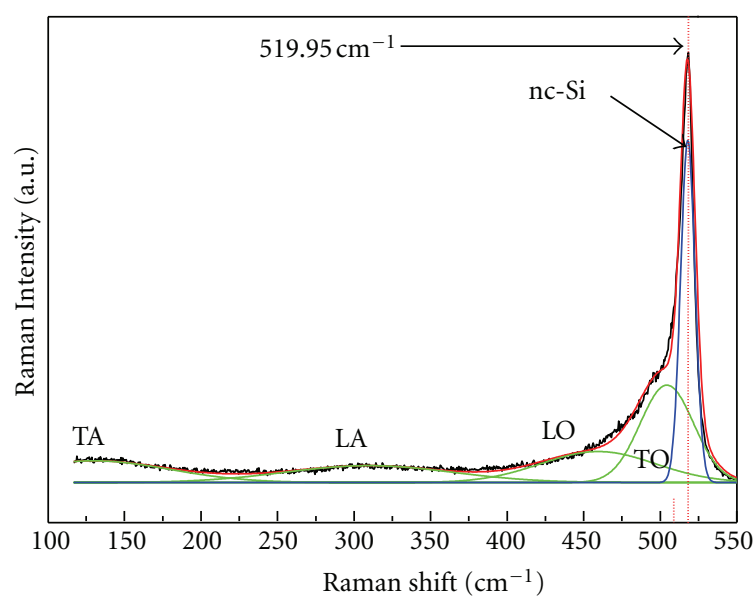

(c)

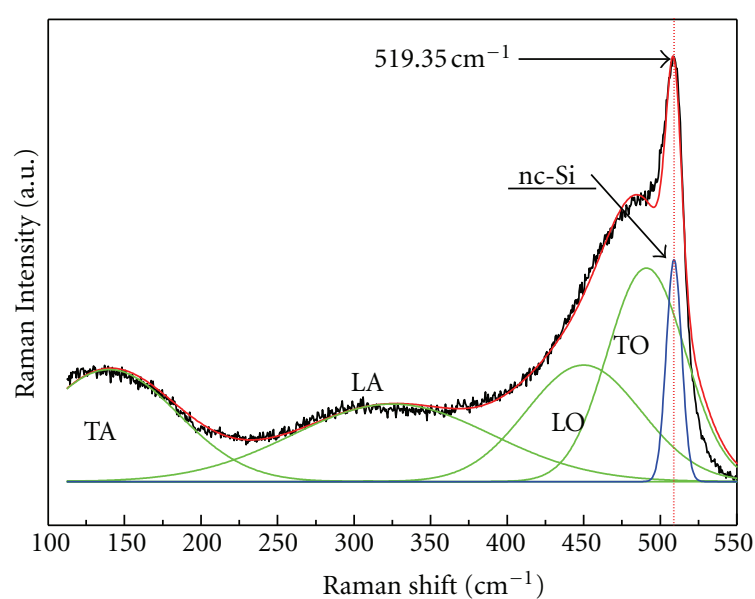

(b)

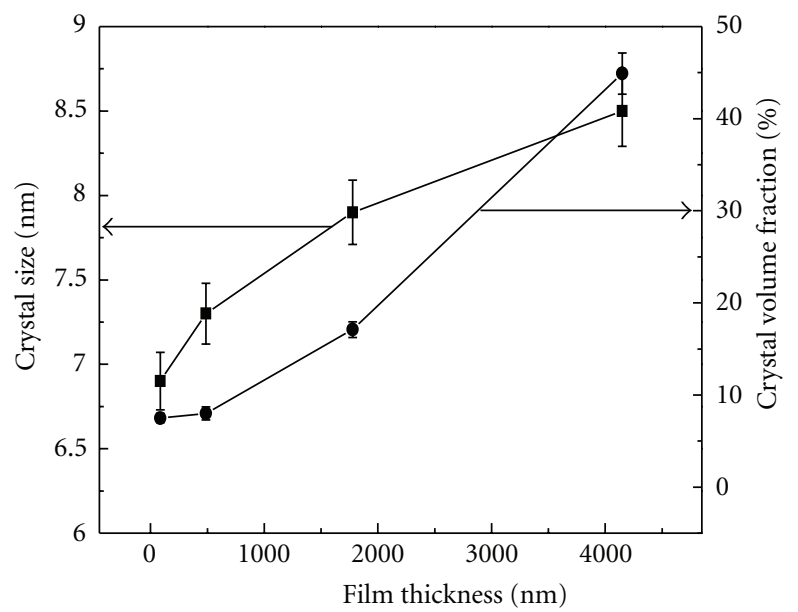

(d)

Figure 3: Raman spectra of the films. The best fits are superimposed in each spectrum. The films were deposited for (a) 10, (b) 180, and (c) $360 \mathrm{~min}$. (d) Crystal size and volume fraction versus film thickness.

3.3. Mechanical Features. Figure 5 shows the mean elastic modulus results, which was calculated using (3) [17].

$$
\frac{1}{E_{r}}=\frac{1-v_{s}^{2}}{E_{s}}+\frac{1-v_{i}^{2}}{E_{i}},
$$

where $E_{r}$ is the elastic modulus of nc-Si:H films. $v_{i}$ and $v_{s}$ are the Poisson's ratios of the diamond tip (0.07) and aSi:H (0.23), respectively; $E_{i}$ and $E_{s}$ are the Young's modulus of the diamond tip (1141 Gpa) and nc-Si:H, respectively. The highest elastic modulus (157 Gpa) was observed when the film thickness was approximately $85 \mathrm{~nm}$; this film was almost amorphous. The elastic modulus decreased rapidly to $\sim 135 \mathrm{Gpa}$ with increasing thin film thickness from 85 to $260 \mathrm{~nm}$ and then increased steadily from $\sim 147 \mathrm{Gpa}$ with further increases in film thickness to $4150 \mathrm{~nm}$.

\subsection{Distribution of Si Nanocrystallites in $4150 \mathrm{~nm}$ Thick} Films. Figure 6 shows a cross-section scanning transmission electron microscopy (STEM) image of nc-Si:H films with a thickness of $4150 \mathrm{~nm}$; the microdiffraction patterns were obtained at various depth positions. The electron microdiffraction patterns obtained at positions $\mathrm{P}_{2}$ (near top surface of the film), $\mathrm{P}_{3}$, and $\mathrm{P}_{4}$ (near middle of the film) clearly exhibit spots related to the presence of nanocrystallites. On the other hand, in the patterns recorded at $\mathrm{P}_{1}$ (top of the film) and $\mathrm{P}_{6}$ (bottom of the film), the intensity of the spots appeared to decrease and spread out [18].

Figure 7 shows the EELS spectra obtained from the specimen shown in Figure 6. The peaks at $\sim 99.9 \mathrm{eV}$ were attributed to $\mathrm{Si}-\mathrm{L}_{2,3}[19]$. The spectra obtained at $\mathrm{P}_{3}$ and $\mathrm{P}_{4}$ appear to have higher intensities than the other spectra. This shows that the distribution of nanocrystallites in the films was not uniform. The stress at the middle of the film, such as regions $\mathrm{P}_{3}$ and $\mathrm{P}_{4}$, is expected to be considerably different from that at positions $\mathrm{P}_{1}$ and $\mathrm{P}_{6}$, which might be related to local variations in the density of nanocrystallites in the film $[20,21]$.

\section{Discussion}

4.1. Nanostructural and Mechanical Features. As observed by SEM, XRD, and Raman spectroscopy, the film thickness was almost proportional to the deposition time. The growth rate 


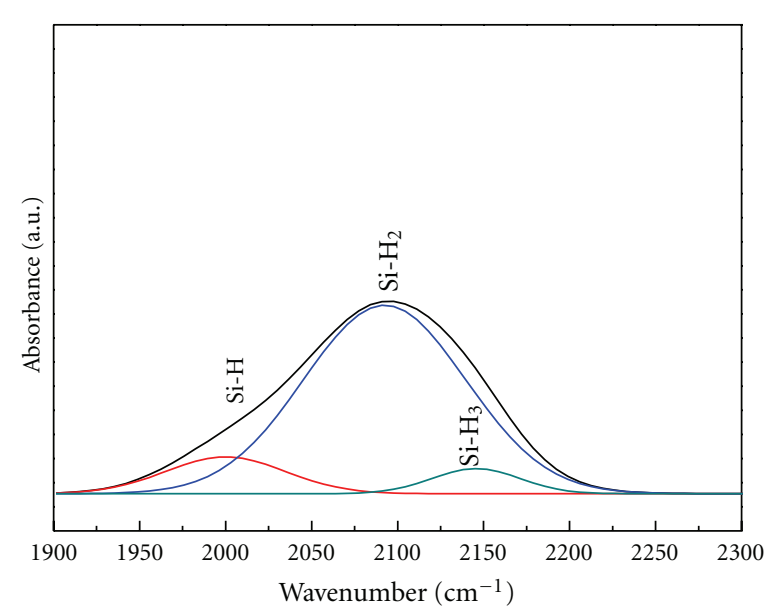

(a)

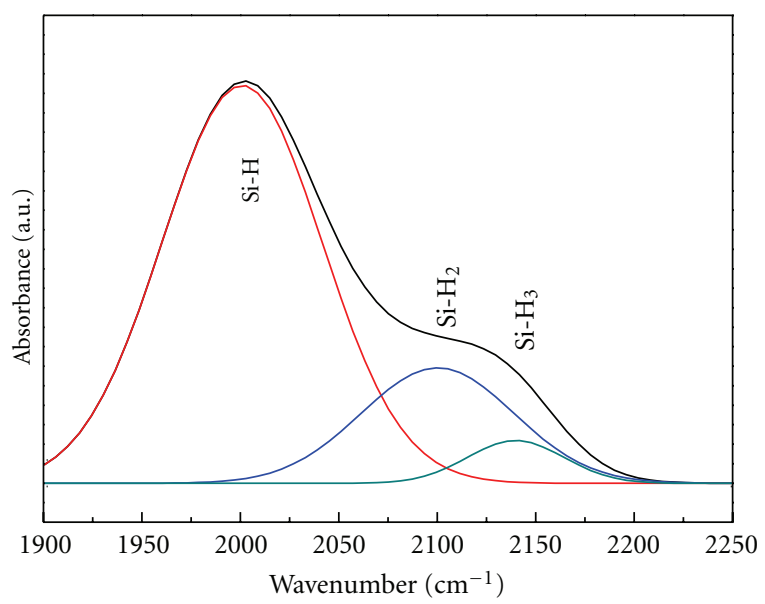

(c)

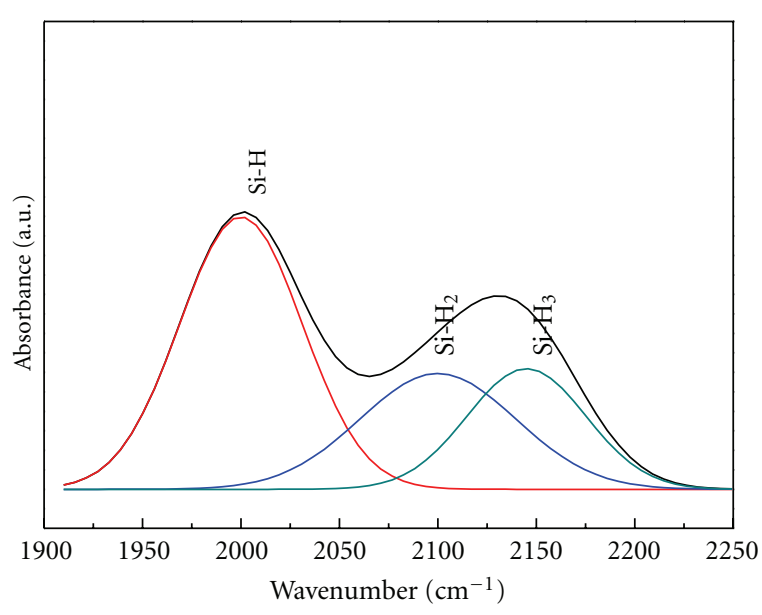

(b)

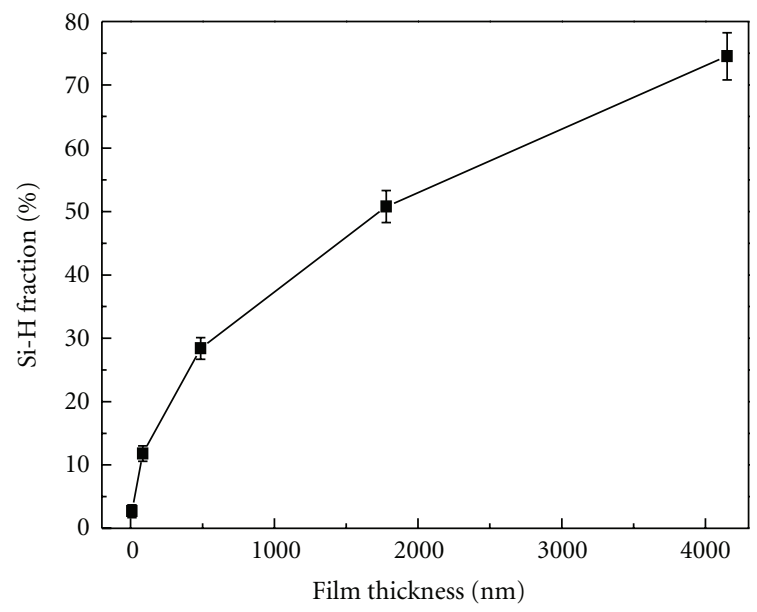

(d)

FigURE 4: FT-IR results. The spectra were obtained from the films prepared for (a) 30, (b) 60, and (c) $360 \mathrm{~min}$. (d) Si-H bonding fractions versus film thickness.

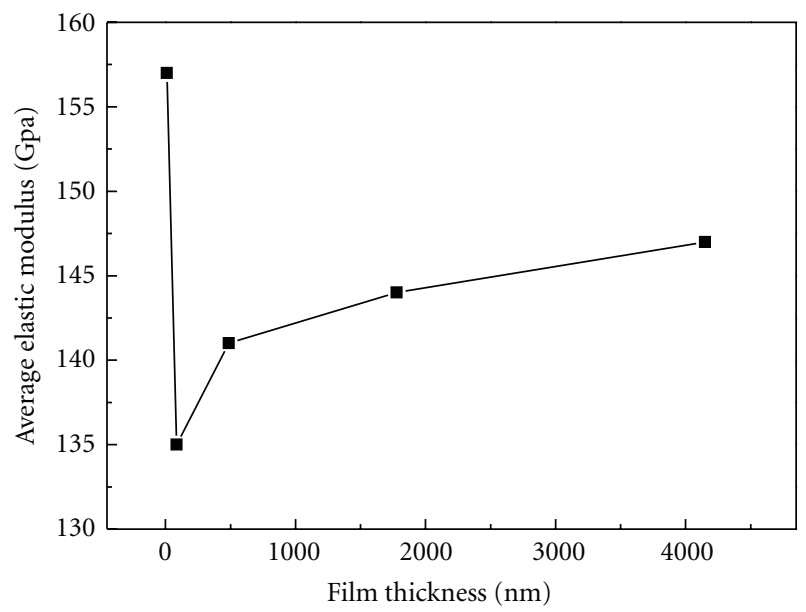

FIgURE 5: Nanoindentation results of the nc-Si:H films. Variation in the elastic modulus with film thickness. 

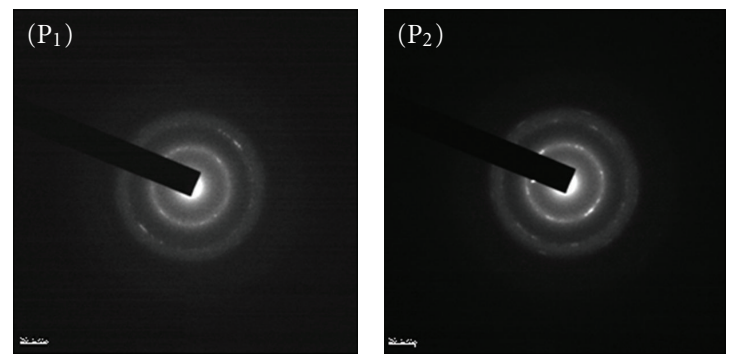

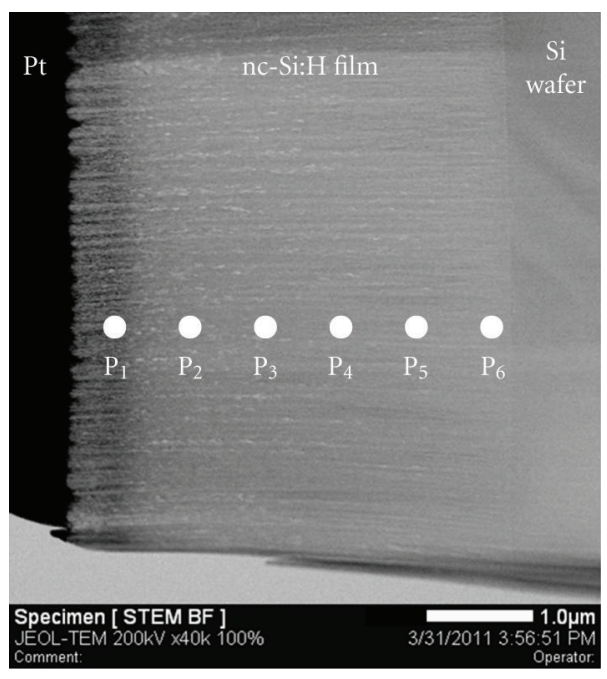

(a)
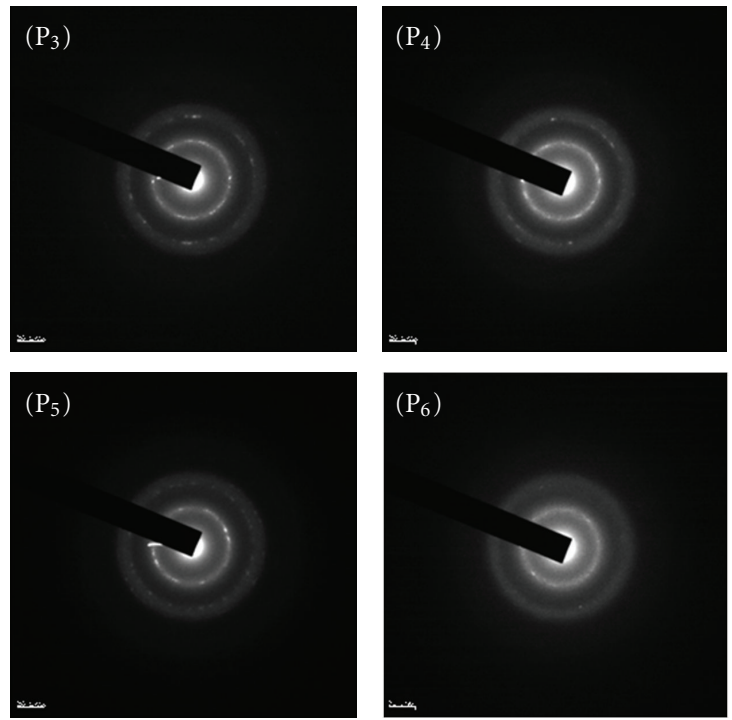

(b)

FIGURE 6: (a) Cross-section STEM image of the nc-Si:H thin films. Arrow m indicates the interface between the substrate (Si-wafer) and nc-Si:H films. (b) Electron microdiffraction patterns were recorded at positions $\mathrm{P}_{1} \sim \mathrm{P}_{6}$ in (a).

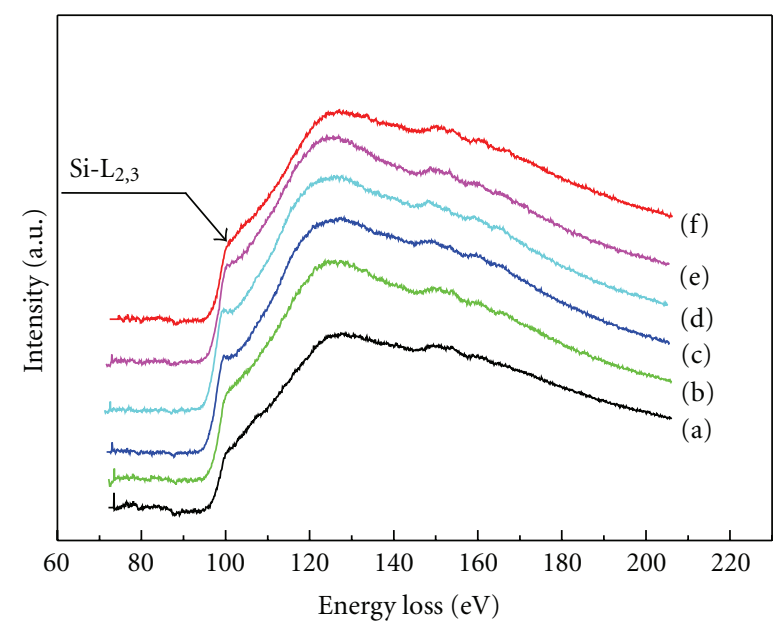

Figure 7: EELS spectra of the nc-Si:H thin films. Spectra (a) (f) were recorded from positions $\mathrm{P}_{1} \sim \mathrm{P}_{6}$, in Figure 6.

was $\sim 11.5 \mathrm{~nm} / \mathrm{min}$ under these experimental conditions. Films $<85 \mathrm{~nm}$ in thickness were almost amorphous. The relative volume fraction of the crystallites increased to $~ 45 \%$ with increasing film thickness from 260 to $4150 \mathrm{~nm}$. The mean size of the $\mathrm{Si}$ nanocrystallites in the films ranged from $\sim 6$ to $\sim 8 \mathrm{~nm}$ under this experimental range (Table 2).
In the initial stage of film growth (deposition time $\leq 10 \mathrm{~min}$ ), the film exhibited a considerably large Young's modulus, which was attributed mainly to the dominant presence of an amorphous Si phase.

The Young's modulus of the film decreased from $\sim 157 \mathrm{Gpa}$ to $\sim 135 \mathrm{Gpa}$ with increasing thickness from 
TABLE 2: Variation in the chemical and physical features of the nc-Si:H thin films with deposition time.

\begin{tabular}{|c|c|c|c|c|c|c|}
\hline $\begin{array}{l}\text { Deposition } \\
\text { time (min) }\end{array}$ & $\begin{array}{l}\text { Film thickness } \\
(\mathrm{nm})\end{array}$ & $\begin{array}{l}d_{\mathrm{XRD}}{ }^{*} \\
(\mathrm{~nm})\end{array}$ & $\begin{array}{c}d_{\text {Raman S. }}{ }^{* *} \\
(\mathrm{~nm})\end{array}$ & $\begin{array}{c}\text { Crystal volume } \\
\text { fraction }(\%)\end{array}$ & $\begin{array}{l}\text { Monohydride volume } \\
\text { fraction }(\%)\end{array}$ & $\begin{array}{c}\text { Elastic modulus } \\
\text { (Gpa) }\end{array}$ \\
\hline 10 & 85 & - & - & - & 2.7 & 157 \\
\hline 30 & 260 & 5.8 & 6.9 & 7.5 & 11.8 & 135 \\
\hline 60 & 490 & 6.2 & 7.3 & 8.0 & 28.4 & 141 \\
\hline 180 & 1780 & 7.4 & 7.9 & 17.7 & 50.8 & 144 \\
\hline 360 & 4150 & 8.1 & 8.5 & 45.0 & 74.5 & 147 \\
\hline
\end{tabular}

${ }^{*} d_{\mathrm{XRD}}$ : crystal size measured by XRD.

$* * d_{\text {Raman S. }}$ : crystal size measured by Raman Spectroscopy.

85 to $260 \mathrm{~nm}$; the $\mathrm{Si}$ nanocrystallites were formed in a-Si. On the other hand, the Young's modulus of the films increased with further increased in film thickness to $4150 \mathrm{~nm}$, reaching $\sim 147 \mathrm{Gpa}$, which is still lower than that for a purely amorphous phase. Moreover, the relative volume fraction of the Si nanocrystallites in the film increased to $\sim 45 \%$. The formation of Si nanocrystallites is believed to be related to the decreasing structural energy of the films during deposition.

The size of Si crystallites is determined mainly by the substrate temperature and the interfacial energy with the amorphous-phased matrix [22]. The structural features of the interface between the crystallites and amorphous matrix are affected by stress in the films. The change in stress within the films appears sensitive to the crystallite-forming species (ions) on the growing film surfaces under these experimental conditions. Consequently the crystallite size increased significantly from $\sim 6$ to $\sim 8 \mathrm{~nm}$ with increasing thickness from 260 to $4150 \mathrm{~nm}$ with a concomitant change in the Young's modulus of the film. More study is currently underway to obtain a better understanding of the interface between the crystallites and amorphous phase.

4.2. Chemical Bonding Features. $\mathrm{Si}-\mathrm{H}, \mathrm{Si}-\mathrm{H}_{2}$, and $\mathrm{Si}-\mathrm{H}_{3}$ bonds are located at either the surface of the Si nanocrystallites or polymeric Si clusters in the nc-Si:H thin films. Considering that the crystallites embedded in an amorphous matrix are nanosized, the surface of the crystallites is believed to be passivated mainly by $\mathrm{Si}-\mathrm{H}$. $\mathrm{Si}-\mathrm{H}_{2}$ and $\mathrm{Si}-\mathrm{H}_{3}$ bonds may contribute to the formation of polymeric chains present in the matrix of the films [23]. Consequently, the change in the relative fraction of the Si crystallites can be related to the relative fraction of $\mathrm{Si}-\mathrm{H}$ bonds, $[\mathrm{Si}-\mathrm{H}] / \sum_{n=1}^{3}\left[\mathrm{Si}-\mathrm{H}_{n}\right]_{n=\text { integer, }}$, in the films. The relative fraction of $\mathrm{Si}-\mathrm{H}$ bonds varied from $\sim 2.7$ to $\sim 74.5 \%$ with increasing film thickness from 85 to $4150 \mathrm{~nm}$. This concurs with the increase in the relative volume fraction of Si crystallites in the film with increasing thickness.

4.3. Local distribution of Si nanocrystallites. The thick film with a thickness of $4150 \mathrm{~nm}$ showed local variations in the concentration of Si nanocrystallites, especially with the distance from the film and substrate interface.

In particular, the EELS and electron microdiffraction patterns obtained from a region near the interface $\left(\mathrm{P}_{6}\right)$ showed a small concentration of Si crystallites. Such a lack of crystallites appears to be related to the fact that the film with a thickness of $85 \mathrm{~nm}$ was mainly amorphous.

On the other hand, the EELS and electron microdiffraction of the middle region $\left(\mathrm{P}_{3}\right.$ and $\left.\mathrm{P}_{4}\right)$ clearly showed the presence of Si crystallites. This corresponds well to the high concentration of crystallites in the films with a thickness range of $1000 \sim 3000 \mathrm{~nm}$.

A lower concentration of Si nanocrystallites is expected near the top surface region $\left(\mathrm{P}_{1}\right)$ of the thick film, which can be attributed to the local distribution of stress within the film. The size and concentration of Si crystallites are influenced significantly by the local distribution of stress within the films.

\section{Conclusion}

The effect of film thickness on the nanostructural, chemical and mechanical features of the nc-Si:H films was investigated. The films were deposited by PECVD at a RF power of $150 \mathrm{~W}$ using $\mathrm{SiH}_{4}$ and $\mathrm{H}_{2}$ as the source gases for a deposition time ranging from 10 to $360 \mathrm{~min}$.

The mean Si nanocrystallite size in the films increased from $\sim 6$ to $\sim 8 \mathrm{~nm}$ with increasing film thickness from 260 to $4150 \mathrm{~nm}$. The nanocrystallite volume fraction changed from $\sim 7.5$ to $\sim 45 \%$, and the elastic modulus increased from 135 to $147 \mathrm{Gpa}$. The relative proportion of $\mathrm{Si}-\mathrm{H}$ bonds in the $4150 \mathrm{~nm}$ thick films (deposited at $360 \mathrm{~min}$ ) was $\sim 74.5 \%$. The formation of Si nanocrystallites is closely related to local chemical bonds as well as to the structural energy state of the films.

\section{Acknowledgment}

This work was supported by the Korea science and engineering foundation (KOSEF) grant funded by the Korea government (MEST) (no. 2011-0003136).

\section{References}

[1] H. Shirai, T. Arai, and T. Nakamura, "Control of the initial stage of nanocrystallite silicon growth monitored by in-situ spectroscopic ellipsometry," Applied Surface Science, vol. 113114, pp. 111-115, 1997.

[2] J. I. Pankove, M. A. Lampert, and M. L. Tarng, "Hydrogenation and dehydrogenation of amorphous and crystalline silicon," Applied Physics Letters, vol. 32, no. 7, pp. 439-441, 1978. 
[3] N. Fukata, C. Li, H. Morihiro, K. Murakami, M. Mitome, and Y. Bando, "Hydrogenation effect on enhancement of photoluminescence of Er and Si nanocrystallites in Er-doped $\mathrm{SiO}_{2}$ synthesized by laser ablation," Applied Physics A, vol. 84, no. 4, pp. 395-401, 2006.

[4] K. Ensslen and S. Vepřek, Journal ofElectroceramics, vol. 7, p. $139,1986$.

[5] J. I. Son, H. H. Kim, and N. H. Cho, "Effect of substrate alternating current bias on the nanostructural features of ncSi: H Films," Journal of the Korean Physical Society, vol. 58, p. 1384, 2011.

[6] A. V. Shah, H. Schade, M. Vanecek et al., "Thin-film silicon solar cell technology," Progress in Photovoltaics: Research and Applications, vol. 12, no. 2-3, pp. 113-142, 2004.

[7] B. Yan, G. Yue, J. Yang, A. Banerjee, and S. Guha, "Hydrogenated microcrystalline silicon single-junction and multijunction solar cells," Materials Research Society Symposium Proceedings, vol. 762, pp. 309-320, 2003.

[8] J. Yang, B. Yan, G. Yue, and S. Guha, in Proceedings of the 31st IEEE Photovoltaic Specialists Conference (PVSC '05), p. 1359, Orlando, Fla, USA, 2005.

[9] J. I. Langford and A. J. C. Wilson, "Scherrer after sixty years: a survey and some new results in the determination of crystallite size," Journal of Applied Crystallography, vol. 11, pp. 102-113, 1978.

[10] D. Han, J. D. Lorentzen, J. Weinberg-Wolf, L. E. McNeil, and Q. Wang, "Raman study of thin films of amorphous-tomicrocrystalline silicon prepared by hot-wire chemical vapor deposition," Journal of Applied Physics, vol. 94, no. 5, pp. 29302936, 2003.

[11] H. Richter, Z. P. Wang, and L. Ley, "The one phonon Raman spectrum in microcrystalline silicon," Solid State Communications, vol. 39, no. 5, pp. 625-629, 1981.

[12] Y. He, C. Yin, G. Cheng, L. Wang, X. Liu, and G. Y. Hu, "The structure and properties of nanosize crystalline silicon films," Journal of Applied Physics, vol. 75, no. 2, pp. 797-803, 1994.

[13] H. Xia, Y. L. He, L. C. Wang et al., "Phonon mode study of Si nanocrystals using micro-Raman spectroscopy," Journal of Applied Physics, vol. 78, no. 11, pp. 6705-6708, 1995.

[14] D. Beeman, R. Tsu, and M. F. Thorpe, "Structural information from the Raman spectrum of amorphous silicon," Physical Review B, vol. 32, no. 2, pp. 874-878, 1985.

[15] P. Jakob and Y. J. Chabal, "Chemical etching of vicinal $\mathrm{Si}(111)$ : dependence of the surface structure and the hydrogen termination on the $\mathrm{pH}$ of the etching solutions," The Journal of Chemical Physics, vol. 95, no. 4, pp. 2897-2909, 1991.

[16] M. H. Brodsky, M. Cardona, and J. J. Cuomo, "Infrared and Raman spectra of the silicon-hydrogen bonds in amorphous silicon prepared by glow discharge and sputtering," Physical Review B, vol. 16, no. 8, pp. 3556-3571, 1977.

[17] W. C. Oliver and G. M. Pharr, "Improved technique for determining hardness and elastic modulus using load and displacement sensing indentation experiments," Journal of Materials Research, vol. 7, no. 6, pp. 1564-1580, 1992.

[18] L. F. Cui, R. Ruffo, C. K. Chan, H. Peng, and Y. Cui, "Crystalline-amorphous core-shell silicon nanowires for high capacity and high current battery electrodes," Nano Letters, vol. 9, no. 1, pp. 491-495, 2009.

[19] M. Schade, N. Geyer, B. Fuhrmann, F. Heyroth, and H. S. Leipner, "High-resolution analytical electron microscopy of catalytically etched silicon nanowires," Applied Physics A, vol. 95, no. 2, pp. 325-327, 2009.

[20] J. Zhou, W. Zhang, L. Wang et al., "Fabrication, microstructure and optical properties of polycrystalline $\mathrm{Er}^{3+}: \mathrm{Y}_{3} \mathrm{Al}_{5} \mathrm{O}_{12}$ ceramics," Ceramics International, vol. 37, no. 1, pp. 119-125, 2011.

[21] S. S. Zhao, H. Du, W. G. Hua, J. Gong, J. B. Li, and C. Sun, "The depth distribution of residual stresses in (Ti,Al)N films: measurement and analysis," Journal of Materials Research, vol. 22, no. 10, pp. 2659-2662, 2007.

[22] H. Hao, J. Xing, W. Li, X. Zeng, G. Kong, and X. Liao, "The effects of substrate temperature on the properties of diphasic nanocrystalline silicon thin films," Optoelectronics and Advanced Materials, Rapid Communications, vol. 5, no. 2, pp. 112-115, 2011.

[23] X. L. Jiang, Y. L. He, and H. L. Zhu, "The effect of passivation of boron dopants by hydrogen in nano-crystalline and microcrystalline silicon films," Journal of Physics, vol. 6, no. 3, pp. 713-718, 1994. 


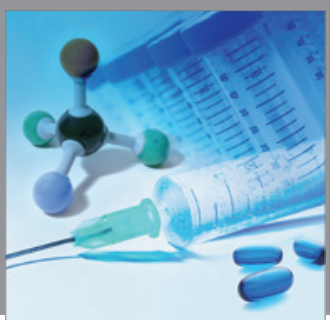

International Journal of

Medicinal Chemistry

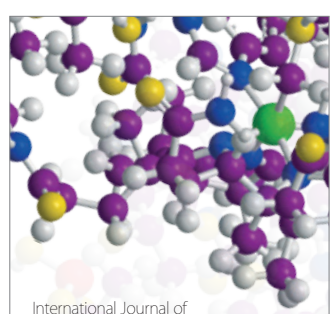

Carbohydrate Chemistry

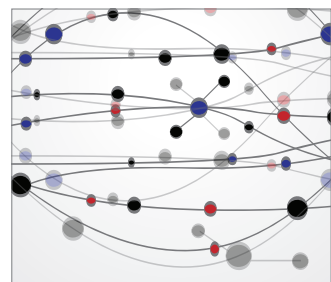

The Scientific World Journal
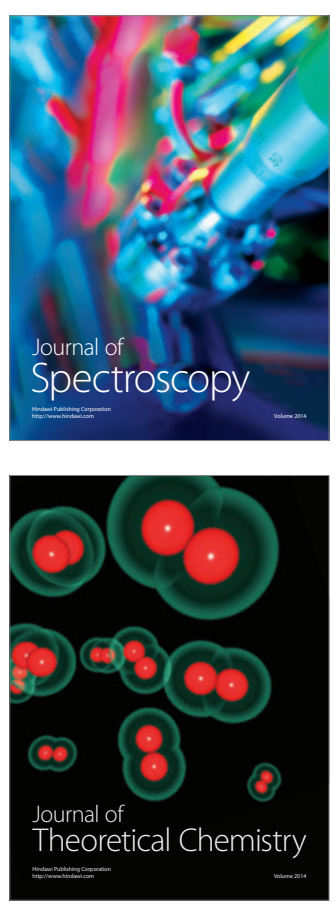
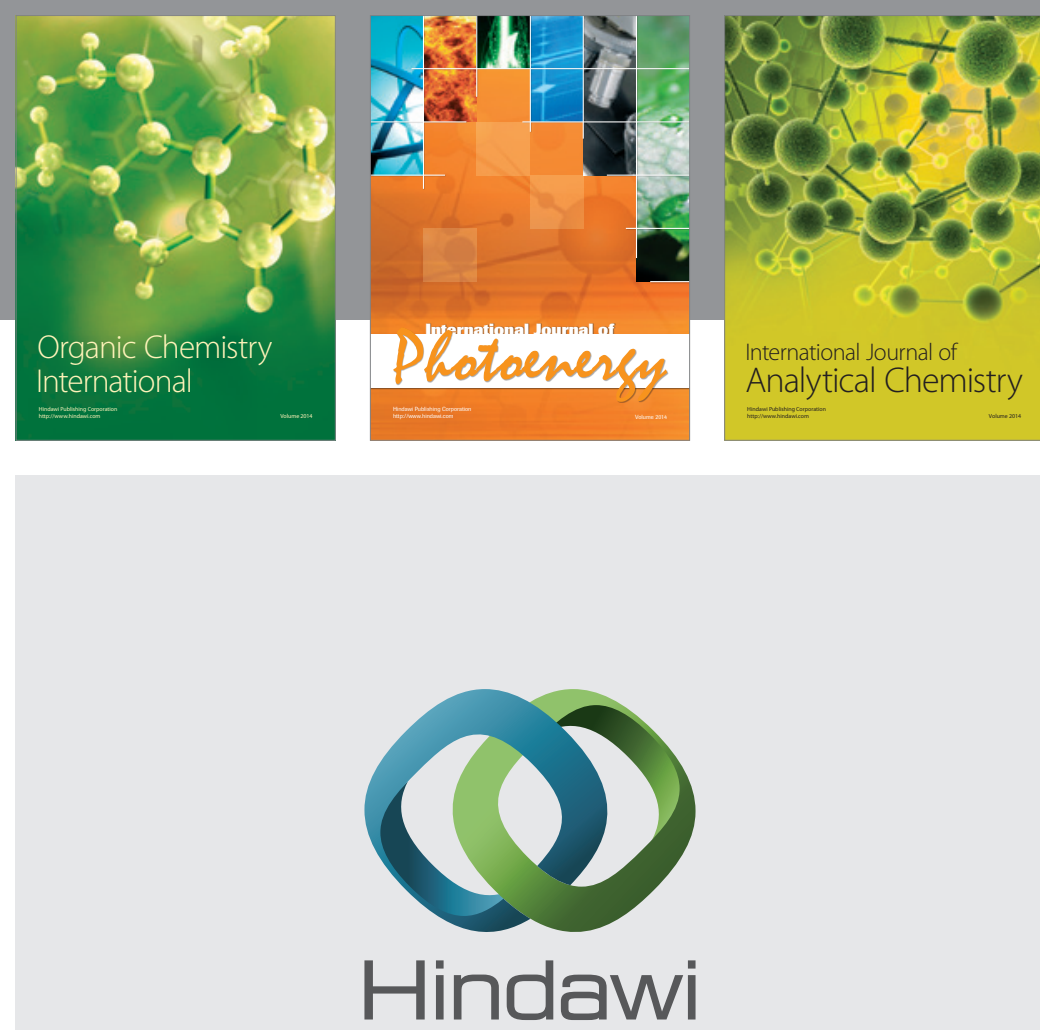

Submit your manuscripts at

http://www.hindawi.com
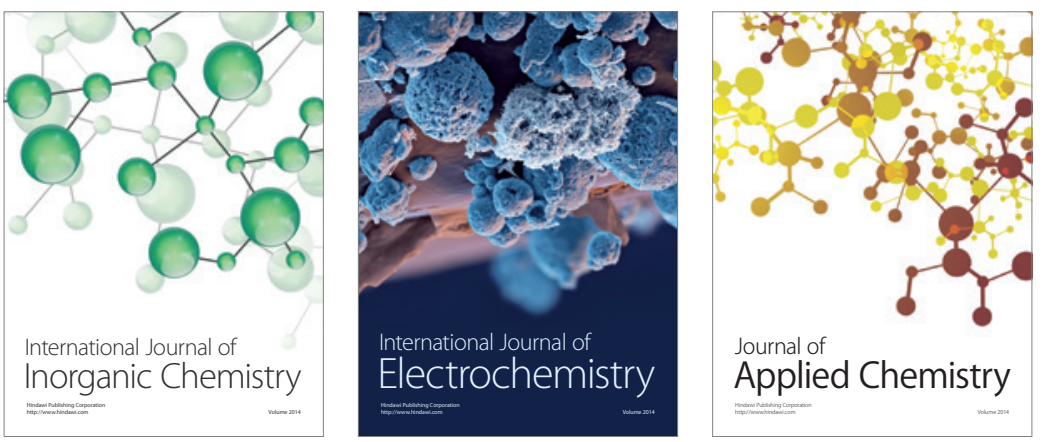

Journal of

Applied Chemistry
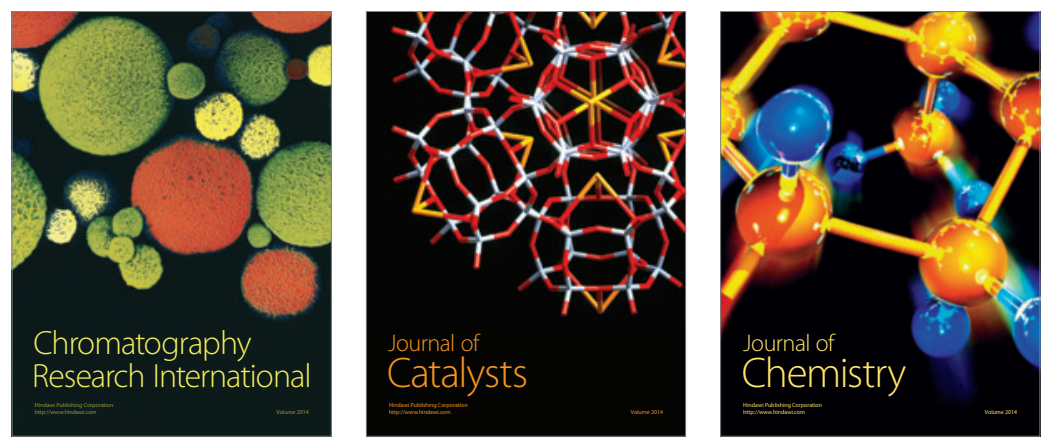
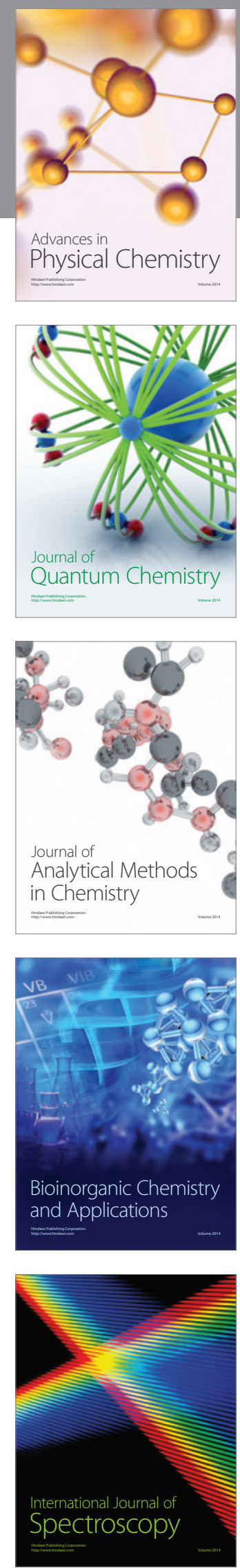